\title{
BOTICAS, MEDICINA E MAXIA
}

Ánxel Vázquez de la Cruz

Médico e escritor

doi:10.17075/mucnoc.2014.055 

Forcadela, M. / T. López / D. Vilavedra (coords.) (2014): Mil e un cunqueiros. Novas olladas para un centenario, Santiago de Compostela, Consello da Cultura Galega. doi:10.17075/mucnoc.2014. pp. 995-1006

Ben habería de contar don Álvaro a emoción e gratitude que sente agora —xa incluído no xénero das clases pasivas- aquel que, rapaz de dez ou doce anos, agardaba ansiosamente nos anos 60 polo Faro de Vigo para ler o Envés: a foto iluminada polas palabras máis fermosas; e xa, para o resto da súa vida, quedar con aquela fulguración e sempre atento á melodía que ía fluíndo en relatos, artigos, novelas, obras teatrais: todo o longo poema da obra de Cunqueiro, onde o noso idioma — «conservalo é a nosa máis importante misión»— vai como un río.

A min paréceme cousa de milagre — aínda que debo dicir que tamén lle mandei unhas nécoras aos organizadores para cumprir este soño- falar no Mondoñedo de Cunqueiro, que é como facelo en Macondo de García Márquez, en Yoknapatawpha de Faulkner, ou en Santa María, de Onetti. Pero, sen menosprezar o poder das nécoras — que tamén recibiu Xosé Luis Axeitos por axudarme na bibliografía e nas conversas, mentres tomabamos, como el di, unhas ghaseosas-, creo que hai unha certa razón, algo esotérica pero de peso, para terme invitado. E debe ser, digo eu, pola miña pertenza xa veterana á seita dos de Cunqueiro da que falaba César Cunqueiro nunha reportaxe da televisión. E, nesa irmandade, creo estar a un bo nivel. Porque, se ben todos os membros desta sorte de relixión acaban falando de Cunqueiro á menor oportunidade e sen contactos previos, os máis iniciados chegamos mesmo a coñecérmonos uns aos outros desde lonxe, como os de certas tendencias sexuais ou os da mafia xaponesa ou, sen ir mais alá, os da provincia de Ourense. E iso aínda que na seita tanto a tipoloxía como as procedencias son moi variadas. Eu, por exemplo, cońecín a moitos en Cataluña: nada raro, tan lido desde moi novo don Álvaro dos poetas cataláns e tan estimat el mesmo naquel país. O máis importante dos alí detectados foi, sen dúbida, Eduardo Galeano. E dun gran mérito tamén porque, como el explicaba, foi durante moitos anos un cunqueiriano clandestino. Até ese punto de envilecemento e mesquindade colectiva levounos a ditadura, mesmo aos seus inimigos e vítimas: non estaba ben visto ler a Cunqueiro en certos ambientes de esquerdas.

Debo afirmar, en primeiro termo, que é imposible que un medico non considere a don Álvaro colega — «illo de bo boticario, zoólogo e gran botánico»—, 
e menos despois de ler Escola de menciñeiros, que debería estar entre os libros oficiais da carreira de medicina. Tamén, no que respecta en xeral á súa obra, está presente esa afinidade súa pola actividade sandadora.

Tanto en Escola de menciñeiros como en Xente de aqui e acolá, amósansenos estes paisanos tan nosos — «de prima doutrina, humoristas se cadra, psicólogos sempre que teñen o poder para sandar», di García Sabell. O propio don Álvaro di que curaban: « talvez porque puñan un gran coidado no trato humano, amén dunha sutileza que lles viría, digo eu, do coñecemento das ordes secretas da Natureza, da cal o home non e máis que unha parcela cuxas lindeiras non se saben».

De identificación tan plena quizais lle viñan certos poderes que don Álvaro non se atreve a definir, pero que, sen dúbida, concilian a maxia coa racionalidade. En palabras de García Sabell, atopan a solución de compromiso entre o pulo da fantasía e o tirón da realidade. «En todo caso —afirma Cunqueiro — trátase de xente de nós, e neste espello teñen ficado rostros do que chamamos ser galego, da insondable profundidade de ser galego; un ser racionalista e supersticioso: un intelectual». E tamén afirmaba: «a miña última pretensión será mostrar a esplendidez da vida cotiá».

Da humilde e espléndida vida cotiá , coa súa parte alícuota —isto de alícuota gustaríalle a don Álvaro- de maxia, humor, perspicacia, melancolía e compaixón, están compostos estes personaxes. Neles, como en Sinbad, en Orestes, en Merlín e en tantos outros está o propio autor que, en palabras de Del Riego, "coñecía como poucos este noso país, ledamente, bondadosamente, con naturalidade. E coñecía aos que vivían nel e non necesitaban outro: cazadores, pescantíns, menciñeiros, labregos, emigrantes e mareantes».

Como non todos os curandeiros tiñan a suficiente cualificación, os poderes precisos, algún que intentou entrar no libro foi rexeitado polo autor: «ti non tes a arte». Ao parecer, non todos aprobaban o particular MIR de don Álvaro.

$\mathrm{Eu}$, que non son crítico literario nin antropólogo nin sequera notario, centrareime nos propios menciñeiros por ser, ao fin e ao cabo, colegas meus. E utilizarei a propia voz de Cunqueiro para destacar os aspectos que coido mais esclarecedores sobre o carácter deles: tan paisano, tan noso.

Os seus nomes compoñen xa unha melodía salutífera: Perron de Braña, Borrallo da Lagoa, Xil da Ribeira, Lamas Vello, Pardo das Pontes, Silva da Posta, O 
señor Cordal, Cabo de Lonxe, O Licho de Vilamor, Loureiro de Pazos, Liñas de Eiris, Novo de Parmuide, Souto de Lires, Penedo de Oiran...

É común neles todos unha certa parsimonia na aproximación ao enfermo, un amigable escoitar, «un ir falando das cousa de ir e vir...».

Unha das calidades máis importantes do menciñeiro, e a un tempo unha das bases da confianza que inspira, é a sabenza dos seus propios limites, do catalogo das técnicas que pode empregar.

Dito xa que hai neles un certo poder de creación, o cal os colocaría no campo artístico, este refórzase con certos ritos máis ou menos racionais ou liturxias misteriosas ou enigmáticas, sempre na idea de que a enfermidade vai máis aló dun trastorno nunha función corporal: é o mundo enteiro do enfermo o que está trastornado.

Ás veces, creo eu, a enfermidade é unha sorte de identificación social, non tanto estigma como distinción, un factor de prestixio: un elemento de atracción cara a unha persoa, se cadra anódina ou anónima, para a que a enfermidade é o máis importante que lle ocorreu na vida en relación cos demais. De aí esa demanda de atención moi ben reflicta nese chiste de Xesucristo, que é enviado de novo ao mundo polo Deus Pai, para ver de arraxar o cristo ese dos ambulatorios. Ponse o bo Xesús de médico nunha consulta, e pasa o primeiro enfermo, parapléxico na súa cadeira de rodas. En dous minutos, xa está de volta na sala de espera, a paso apresurado e empurrando a cadeira. «E o novo que tal?», é a pregunta unánime. «Nada, — contesta irado o paciente — coma todos: nin mirou para min nin sequera me preguntou como me chamo: levántate e anda, e ao carallo!».

Iso non lle pasaría nunca ao pobre paralítico cun mencińeiro.

As técnicas deles varían duns a outros e tamén, até certo punto - porque todos atenden en corpo e alma- as especialidades: compoñen ósos, eliminan verrugas, empregan fórmulas de psicoterapia tales como cambiarlle o nome ao enfermo, inventarlle outra identidade ou, ao usureiro, receitarlle unha tempada de mendicidade nunha sorte de laborterapia condutista. Pero tamén empregan sangrías, réximes de comidas, sinapismos, etc.

Ás veces, dan longos paseos co enfermo, pasa a noite incluída nun palleiro ou nunha fonda ou ensinan a respirar con técnicas tipo ioga. Aconsellan comidas, baños quentes e, ás veces, a ociosidade: «para certos enfermos a mellor medicina é a vaguidade». 
Outros botan man de poderes máis potentes e desenvolven capacidades de adivińación. Tamén de extirpación ou expulsión de ánimas, o que xa pertencería máis ben ao campo dos transplantes

Moi brevemente lembro agora - textualmente en gran parte e de forma resumida - algúns deles, dos menciñeiros e dos enfermos, que me parecen máis arquetípicos, e a forma en que se entregaron á súa propia morte.

Perron de Braña: «Viña moito pola botica de meu pai».

É un dos máis xerais: sangraba, diagnosticaba pola voz: «hai nove tonos». Dáballe moita importancia ao ben durmir, mesmo até deitarse á beira do doente, fose muller ou crego, e compasaba a súa respiración. Contáballes historias e os enfermos devecían por elas. Púñalles adiviñanzas. Ninguén llas sacaba, aínda que, ás veces, participaba toda a familia, toda a aldea. O Grilo de Abeledo sacáralle unha e o crego de Labrada nunca puido con ela: «foise o Grilo — dicía medio cabreado o crego no enterro- sen darme a correcta das sete zocas que calzaban catro homes e ningún era coxo».

Perrón era da casca amarga, ou sexa, republicano, como varios outros que Cunqueiro non se priva de sinalar con certa compracencia.

Borrallo de Lagoa:

Movíase preferentemente no campo psiquiátrico. Podían deixalo só no monte cun tolo irado e non lle facía nada: «obedecíano e quedábase». Cambiáballe o nome aos tolos e inventáballe unha biografía. A un que se chamaba Secundino dicíalle: «ti es Pepito e nada máis. Contesta so por Pepito». Dicíalle que estivera na Habana e tivera unha carboaría en santa Clara $21 . .$.

Estaba algo especializado nos afrixoados: xente que se entrisca, cánsase, enfraquece, desavece a comida. El mesmo fora un afrixoado e curou a base de aprender a ler e porque vendeu unha leira e foi pasar un mes a Ourense. Volveu novo. Contaba e non paraba dos cafés cantantes. Aos afrixoados convencíaos de que non o estaban: dicíalles que tiñan, en realidade, algo orgánico: unha pedra na illada ou unha flegma crónica. A un tal Listeiro, deprimido e que se deixaba morrer, déralle por blasfemar e díxolle á Borrallo que «a vida era unha merda, e que el non se colgaba por non darlle gusto a unha nora que tiña». Acabou levando ao propio Borrallo ás costas tal como lle profetizara o sandador, no máis cru da loucura, a 
unha romaría de San Cosme. Para completar o prodixio, a nora marchou servir para Barcelona.

Valía máis que Conxo", dicía a xente.

Apareceu nunha cuneta no 36 cun tiro na cabeza.

Parece que o estou vendo na botica de meu pai.

Lamas Vello:

Empregaba o amigable escoitar para facer unha historia clínica exhaustiva. Teorizaba sobre a etioloxía e a patoxenia: «a enfermidade non cha botou ninguén. Están en un: un mal soño, unha anguria, unha envexa, unha teima contra dalgún, pódese volver unha enfermidade. Unha persoa humildosa, calada, amiga, esmoleira, está inmunizada contra moitas doenzas. Os soberbios, avaros, irados, sobresaltan o sangue e adoitan o corpo para que lles veña unha doenza».

Ás veces, a enfermidade hai que pórlle un nome humano. Moitos nin sequera están realmente enfermos. E que se anoxan. Contaba moi ben as historias, mesmo contos. A mellor cura é a vaguidade, acostumaba dicir. Ao Folgo de Vilamea, sumamente grave, diagnosticouno "de ansia, de ansia e nada mais que ansia», e mandouno a pedir esmola unha tempada. Volveu san e fíxose dadivoso e até derrochón.

\section{Pardo de Montes:}

Moi lido e gran compoñedor de ósos. Viñera de Cuba. Trataba de vostede aos enfermos durante a consulta, e distinguía 13 pulsos.

A súa teoría patoxénica baseábase nos ventos. Temos no corpo nordés, xistral ou vendaval, e o de dentro abanease nunha ou noutra parte onde estea soprando.

Puńa na receita entre o nome e a dose a palabra vervigracia — «laúdano, vervigracia, 3 gotas»— e sempre á luz dunha vela.

Cando o 36, pasou moito medo dun médico — quen sabe si por ciúmes profesionais - Del dicía en cubano: «este me va a mandar a coger postalitas».

Silva da Posta:

Enfermeiro de manicomio e músico en Bos Aires. Tocaba o harmonio de valixa. Trataba moito con asuntos de ánimas 
A Cachizas, un enfermo xa do manicomio en Arxentina, onde se fixeran amigos, que teimara seguido con quedarse viaxando pola aldea despois de morto, díxolle que bastaba con levar un espertador á tumba e ter algo que facer por aquí. Decidiu Cachizas deixar uns cartos enterrados e saír controlar que a muller non volvese casar. Empeorou rapidamente Cachizas e, en pouco tempo, xa estaba enterrado co espertador. Houbo gran expectación e medo cando soou na hora programada, pero non volveu soar porque Cachizas non volveu darlle corda.

—Ultimamente andaba algo xordo e quizais non oíu o espertador — dixo Silva.

De todos modos, un tal Vizoso deixou testemuña dos poderes de Silva cando no alto da xesta foi apremado por el para coller una ánima perniciosa que había que chocar. Quere dicir enganala e darlle terra. Atraeu a ánima a unha pelica de ovella e, cando a tivo dentro, díxolle en arxentino:

—Amigo Victoriano — soubo que o nome era Victoriano despois de chamarlle un innúmero de nomes ao azar, até que, ao oír o apropiado, se remexeu a ánima dentro da pelica— ¡qué alegría! Cuanto tiempo sin verlo a usted y la familia...

E así, despois de moitas zalamerías, cravou a navalla no medio da pelica que se remexía, até que parou; atáronlle, entón, unhas correas e despois mexáronlle enriba. Quedou a ánima coa navalla cravada.

Lamentábase Silva de deixala alí: unha Soligen marca "Los dos macacos"

E marchábase, despois de semellante intervención, teimando naquela navalla Soligen.

A Cabo de Lonxe - habitual da botica do pai- preguntoulle Cunqueiro onde era lonxe:

-Ai ¿quen llo sabe? Xa ao meu avó llo chamaban

Tińa uns principios deontolóxicos moi firmes. Cando o acusaron de andar en abortos, dicíalle a don Álvaro: deso nada. "Cousa ben distinta e darlle as rapazas unhas herbas para que non empreńen. Iso non lle fai mal a ninguén”.

Braulio de Labrada salvárase dun raio porque alguén, luminoso e redondo, tirou del amarrándoo dun brazo e levouno a moita distancia do castińeiro onde se refuxiara, que quedou carbonizado. Para demostrar o tirón do brazo, ensinaba un certificado dun xastre de Lugo, coas medidas anteriores ao suceso, mentres estendía os dous brazos, un deles moito máis longo. 
Cando lle dicían que a figura luminosa podía ser a fúlgura do raio, el sinalaba o brazo.

E non seria o anxo da garda?» — díxolle Cunqueiro.

Ou un encanto compasivo ou san Cosme, ou un defunto que pasaba por alí... - replicou, moito máis aberto o espectro terapéutico, Braulio de Labrada.

\section{Enfermidades e taras}

Monteiro de Rubias foi tomar os baños a Covas por prescrición de Pita de Sancobade. Tomounos en minguante e sentáronlle mal. Adelgazou, saíronlle tirizós e, o peor de todo, púxoselle unha sombra onda el. Saíra do mar con ela. Quizais era dalgún afogado. A sombra era pequena, frioleira e daba mal durmir. A noite enteira dando voltas. A sombra non comía. Monteiro, sempre doente, canso, sen mais compañía cá da sombra. Apoiábase nela como nun bastón cando ía pasear. Cando chegou o verán, Pita mandouno outra vez a Covas.

A ver si te rectificas. Ou te reinicias, diría hoxe.

Cando saíu da auga, a sombra quedara no mar. Monteiro berrou por ela e chorou un día enteiro no areal. A sombra non volveu e Monteiro foise so para Rubias. Pouco despois finou, «aborrecido, inapetente, canso, canso».

O fillo - que traballaba na Seat en Barcelona- deulle esta explicación a Cunqueiro ante a súa muller albaceteña:

-Es como si a uno le hubiesen quitado el cuerpo de afuera y quedase suelto en el mundo el cuerpo de adentro.

A albaceteña choraba.

— Ten medo de que lle pase o mesmo ao noso Antonciño — dixo, entón, o fillo de Monteiro.

Souto de Lires, Manuelińo, naceu coa cachola algo ladeada, o brazo dereito máis curto que o esquerdo e o pé esquerdo medio volto. Para o da cabeza mercou un sombreiro e arranxouno para pońelo de fronte, de modo que disimulaba a cousa; a curtidade do brazo até podía ser vantaxe para a escopeta ou o legón. Pero o que o traía moi desgustado era o do pé. 
— ¡Non mo merezo, coño!

Rexeitado no servizo militar, tamén en cabalaría ou artillaría — onde el consideraba que podía facer un bo papel—, comezou a andar só polo monte a amurriarse e a deitarse á nugalla. Un día, sentiuse morrer e dispúxose moi calado e quentińo no seu leito. Morreu á tardiña.

Ao pouco tempo, ía o crego de Seixo, don Perfecto Illade, cara a Teixeiro, e veu un corvo a dúas varas del, que lle recordou a alguén: tiña a cabeza ladeada, unha ala máis curta que a outra e a pata esquerda volta:

— ¿Que fas aquí, home? — preguntoulle o crego.

— Voando non hai coxos — berrou o corvo.

Don Perfecto Illade explicaba o asunto:

—En primer lugar, hemanos, los caminos del señor son imprevisibles. En segundo lugar, el que la sigue la consigue.

Secundino Prieto:

Doente moi lúcido da súa condición:

—Dóeche algo?

—Non me doe nada, home. Pasa que estou doente. Paréceche pouco?

Dixo que el chegara a ver o seu corpo por dentro e viu como funcionaba. «Igualito que un reló», e que algo se lle soltara a el. Un botón. E cando volvía de ver a súa moza Rosiña.

Enfraqueceu, entristeceu, quedou sen apetito, tratando en van de cuspir o botón solto. Resignado ao asunto, ocorréuselle pasarlle a enfermidade a outro. Non por mal. Pasarlla a un amigo que lle fixese compaña e fose con el aos baños. Era un mal bo de levar. Mesmo ofreceulle o traspaso ao propio don Álvaro. Repartirían todo o capital, e respecto a Rosiña: «o que se tratara».

Os médicos dicíanlle que non tińa nada e que traballase.

«Un día calquera ergueuse de cedo, mandou que lle mudasen a cama e lle puxeran as mellores sabas, deitouse e morreu». 


\section{As Mortes}

Perron de Braña: despois de axudar no vareo das castańas, meteuse na cama e díxolle á muller que lle dese conversación. Seguindo os seus propios métodos, dixo a muller:

-Unha mosca, catro medias moscas e mosca en media ¿cantas moscas son? E xa ía a dicir Perrón catro moscas e media, cando cun tosico de nada entregou a alma.

Xil da Ribeira: Mencińeiro que xa lle viña de estirpe moi dado a teorizar. Estaba en contra do leite por razóns ben naturais.

Ao final, fíxose xastre de doentes. Dicíalle á familia cando un ía morrer para facerlle o traxe e que estivese decente...

Finou un día que para iso saíu da casa da súa irma. Sentouse nun cómaro, abriu o paraugas e morreu.

Ídeme buscar dentro dunha hora e traédeme sentado nunha silla.

O Coxo de Entrebo: Enviciado coas cabareteiras e cazador empedernido. Volveuse curandeiro e adiviño despois dunha expedición golfa a Madrid. Apareceu morto no monte coa cara comesta por unha animalia:

- Un lobo non foi - dixo un que o vira falar cunha loba e a loba dicía que non coa cabeza.

Mel de Vincios: Botaba os demos do corpo a patadas e, non obstante, era moi ilustrado e experto en leis até o punto de pasarse da medicina aos preitos.

Os ferreiros de Taramundi que ían ao mercado da Veiga vírono morto pasear polos montes recollendo herbas. Coa mesma gorra de viseira, coa mesma zamarra e o seu can Nei, tamén defunto, parando unhas perdices nas brańas de Prior

Os indios americanos chamábanlle aos ríos camiños que andan. Álvaro Cunqueiro — que amaba especialmente os ríos- é o gran río da nosa tribo, o río da nosa lingua, que é tanto como dicir do noso ser.

É, tamén, o menciñeiro de todos nós: calquera que abra unha páxina, calquera páxina súa, sentirá ese bálsamo fluvial. 
